\title{
Dietary patterns and metabolic phenotypes in Brazilian adults: a population-based cross-sectional study
}

\author{
Dayana LM Pereira ${ }^{1, *}$, Leidjaira L Juvanhol ${ }^{1}$, Daniele CG Silva ${ }^{2}$ and Giana Z Longo ${ }^{1}$ \\ 'Departamento de Nutrição e Saúde, Programa de Pós Graduação em Ciência da Nutrição, Universidade Federal de \\ Viçosa, Campus Universitário, Viçosa, MG 36570-900, Brazil: '2Centro de Ciências Biológicas e da Saúde, \\ Universidade Federal do Oeste da Bahia, Barreiras, BA, Brazil
}

Submitted 16 January 2019: Final revision received 15 May 2019: Accepted 28 May 2019: First published online 1 October 2019

\begin{abstract}
Objective: Dietary patterns have been pointed out as useful diet quality indicators, but evidence about their relationship to metabolic phenotypes is still scarce. Thus, the present study aimed to verify the relationship between dietary patterns and metabolic phenotypes in Brazilian adults.

Design: Cross-sectional study. A food consumption frequency questionnaire assessed food consumption profiles. Metabolic phenotypes were defined based on the criteria of the National Health and Nutrition Examination Survey: overweight or normal weight and metabolically healthy (MHOW and MHNW) or unhealthy (MUOW and MUNW). Dietary patterns were established through exploratory factor analysis and principal component analysis. The associations were tested using multinomial logistic regression.

Setting: Viçosa, Minas Gerais, Brazil.

Participants: Individuals ( $n$ 896) aged $20-59$ years of both sexes, selected using probabilistic sampling.

Results: Three dietary patterns were identified: Unhealthy pattern (alcoholic beverages, oils and fats, condiments, soda and juice, sugars and sweets, snacks, and meat and derivatives), Traditional pattern (culinary preparations, beans, milk and dairy products, and coffee and tea) and Healthy pattern (vegetables and fruits, whole grains, chicken and fish, and skimmed milk). Unhealthy pattern was positively associated with the MHOW and MUOW phenotypes in the fourth quartile $(\mathrm{OR}=1 \cdot 84 ; 95 \% \mathrm{CI} 1 \cdot 06,3 \cdot 22)$ and in the third (OR $=1.94 ; 95 \% \mathrm{CI} 1 \cdot 11,3 \cdot 39)$ and fourth $(\mathrm{OR}=2.56$; $95 \% \mathrm{CI} 1.41,4.64)$ quartiles of consumption, respectively. Healthy pattern was also associated with these phenotypes.

Conclusions: Both the pattern comprising energy-dense foods and the healthier pattern were associated with overweight phenotypes among Brazilian adults.
\end{abstract}

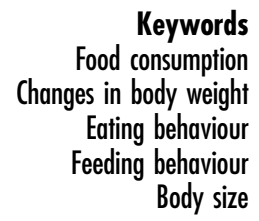

The nutritional transition in Brazil is composed of changes in the population's dietary habits from a traditional dietary pattern, composed mostly of culinary preparations, to a Western pattern rich in high-energy foods. As a consequence, a significant increase in the prevalence of overweight people and associated diseases has been observed $^{(1,2)}$.

In nutritional epidemiology, population dietary intake is traditionally evaluated from macro- and micronutrient counts and energy intake ${ }^{(3,4)}$. However, more recent studies have evaluated population food consumption based on nutrients and foods alongside identification of dietary patterns. Among these, authors have described ones defined according to locality, such as 'Mediterranean', 'Western' and 'Traditional' patterns ${ }^{(4-6)}$. This new approach has enabled a better understanding of the association between population dietary intake and health outcomes ${ }^{(4,5,7,8)}$ since each of these patterns has a different nutritional profile and, therefore, relates differently to lifestyle and human health ${ }^{(6)}$.

Metabolic phenotypes, in turn, are metabolism variations in individuals with similar $\mathrm{BMI}^{(9)}$. Metabolic changes such as hypertension, dyslipidaemia, insulin resistance and inflammation can be identified in both overweight and normal-weight individuals. Thus, four phenotypic groups have been described: metabolically healthy and normal weight (MHNW); metabolically unhealthy but normal weight (MUNW); metabolically healthy but overweight 
(MHOW); and metabolically unhealthy and overweight (MUOW) ${ }^{(9,10)}$.

The prevalence of metabolic phenotypes in Brazilian studies has varied according to the population studied and the classification criteria adopted: $18 \cdot 8-20 \cdot 7 \%$ for MUNW, $13 \cdot 1-18.5 \%$ for MHOW and $48 \cdot 1-55.8 \%$ for MUOW $^{(11,12)}$. The high prevalence of these phenotypes in the population is worrisome, especially in relation to MUNW and MHOW, which are considered transitional phenotypes $^{(4)}$. Thus, they should be the target of interventions aimed at lifestyle changes to prevent the future development of adverse metabolic and cardiovascular outcomes $^{(1,2,9)}$.

Other authors have identified the influence of sociodemographic and behavioural factors on metabolic phenotypes $^{(13,14)}$ as well as the associations of dietary patterns with excessive weight ${ }^{(1,15,16)}$ and isolated metabolic alterations $^{(3,6,17)}$. Nevertheless, research on the dietary intake-metabolic phenotype relationship is scarce. We identified only two studies evaluating the association of food intake with metabolic phenotypes among Americans ${ }^{(16,18)}$ and we found no studies investigating dietary patterns.

Thus, the objective of the present study was to investigate the relationship between dietary patterns and metabolic phenotypes in a population-based study conducted with Brazilian adults.

\section{Methodology}

\section{Design and sampling procedure}

The present study is part of the research project 'Metabolic syndrome and associated factors: a population-based study in adults in Viçosa-MG', which was approved by the Human Research Ethics Committee of the Federal University of Viçosa (opinion number 008/2012). All participants signed the free and informed consent form.

This is a cross-sectional study carried out with the adult population (20-59 years old) of both sexes living in the urban area of Viçosa, Minas Gerais, Brazil. The sample size was calculated using the OpenEpi program considering the following parameters: reference population of $43431^{(16)}$, expected prevalence of $50 \%$ for the phenomenon (multiple outcomes), $95 \%$ CI, $4.5 \%$ sample error and design effect of 1.7 . In addition, $10 \%$ was added to compensate for refusals and losses and $10 \%$ to control for confounding factors, obtaining a final sample size of 957 individuals. We used probabilistic sampling to select in two stages.

The sampling process was carried out through conglomerates. The first-stage units were the census tracts (census units defined by the Brazilian Institute of Geography and Statistics) and the second-stage units were households. We selected thirty sectors out of the ninety-nine existing in the urban area of the city of Viçosa, Minas Gerais, through a random procedure, without replacement. The blocks were identified and drawn for each census sector based on their maps. After this procedure, a block corner was drawn for each field in which the research would take place, adopting clockwise direction. As the calculated size of the sample required was 957 individuals, approximately thirty-two individuals were investigated per census tract.

A detailed description of the methodology for our study can be found in Segheto et al. ${ }^{(19)}$.

\section{Collection of clinical and antbropometric data}

Data collection took place in the period from 2012 to 2014. Interviewers and surveyors were trained by the research coordination team to carry out the data collection. Laboratory and clinical tests and anthropometry were performed. Blood samples were collected by intravenous puncture using a Vacutainer system (Becton Dickinson, Plymouth, UK), after a $12 \mathrm{~h}$ fast, to determine levels of glucose, total cholesterol, HDL-cholesterol, TAG and high-sensitivity C-reactive protein. Serum samples were separated from whole blood by centrifugation at $3000 \mathrm{rpm}(2000 \boldsymbol{g})$ for $15 \mathrm{~min}$. Glucose was determined by the enzymatic glucose-oxidase method; total cholesterol, HDL-cholesterol and TAG by the calorimetric enzymatic method using commercial Bioclin kits (São Paulo, SP, Brazil); insulin by ELISA (Linco Research ${ }^{\circledR}$, St. Charles, MO, USA); and high-sensitivity C-reactive protein by immunoturbidimetric assay. The homeostasis model assessment of insulin resistance index was used as an indicator of insulin resistance, calculated from the following formula: [fasting insulin $(\mu \mathrm{U} / \mathrm{ml}) \times$ fasting glucose $(\mathrm{mmol} / \mathrm{l})] / 22 \cdot 5$.

Blood pressure was measured in duplicate on the same upper limb while the individual was sitting. The first measure was obtained after a $5 \mathrm{~min}$ rest and the second one 15 min afterwards. The mean of the two measurements was calculated and considered as the final value. For the measurements, we used an automatic blood-pressure monitor with clamp (model Omron HEM 629, Weymouth, UK).

Body weight was measured on a digital scale (model Ironman $^{\mathrm{TM}}$ BC-554; Tanita Corporation, London, UK) with a capacity of $200 \mathrm{~kg}$ and accuracy of $100 \mathrm{~g}$, and height was measured to the nearest $0.1 \mathrm{~cm}$ using a metal stadiometer (Welmy In Wall, Santa Barbara d'Oeste, São Paulo, Brazil). BMI was calculated using weight and height measurements and classified as normal weight $\left(\mathrm{BMI} \leq 24.99 \mathrm{~kg} / \mathrm{m}^{2}\right)$ or overweight $\left(\mathrm{BMI} \geq 25.00 \mathrm{~kg} / \mathrm{m}^{2}\right)^{(20)}$.

The National Health and Nutrition Examination Survey (NHANES) ${ }^{(9)}$ was used for the definition of metabolic phenotypes. The following metabolic changes were considered to determine the phenotypes: high blood pressure $(\geq 130 /$ $85 \mathrm{mmHg}$ or hypertensive medication use); hypertriacylglycerolaemia (fasting TAG $\geq 150 \mathrm{mg} / \mathrm{dl}$ ); low HDL-cholesterol $(\leq 40 \mathrm{mg} / \mathrm{dl}$ for men and $\leq 50 \mathrm{mg} / \mathrm{dl}$ for women or lipid-lowering medication use); hyperglycaemia (fasting glucose $\geq 100 \mathrm{mg} / \mathrm{dl}$ or antidiabetic agent use); insulin resistance (homeostasis model assessment of insulin resistance 
Dietary patterns and metabolic phenotypes

Table 1 Food groups extracted, for factor analysis, from the food consumption frequency questionnaire completed by adults ( $n$ 896) aged 20-59 years of both sexes, Viçosa, Minas Gerais, Brazil, 2012-2014

\begin{tabular}{|c|c|}
\hline Food group & FFQ food items \\
\hline Food \& beverage outlets & $\begin{array}{l}\text { Strogonoff, white rice, polenta, farofa flour, flour, sweet potato, cooked cassava, vegetable soup, broths, } \\
\text { soup, pasta soup with vegetables, pasta (pasta, Miojo }{ }^{\circledR} \text {, lasagne) }\end{array}$ \\
\hline Beans & Beans, tropeiro beans, feijoada \\
\hline Milk and dairy products & Dairy milk, whole milk, fermented milk, yoghurt, cheese, regular and light cream cheese \\
\hline Spices & $\begin{array}{l}\text { Mortadella, ham, salami sausage, sausage, olives, green corn, Sazon }{ }^{\circledR}, \text { Knoor }{ }^{\circledR} \text { broth, salad dressing, } \\
\text { ketchup, mustard }\end{array}$ \\
\hline Vegetables and fruits & $\begin{array}{l}\text { Lettuce, garlic, cabbage, watercress, arugula, zucchini, chayote, broccoli, cauliflower, cabbage, beetroot, } \\
\text { carrot, tomato, vinaigrette, pineapple, melon, watermelon, orange, clementine, guava, peach, banana, } \\
\text { apple, pear, papaya, grape, strawberry, plum, açai, fruit salad, fruit juice generally (except orange), orange } \\
\text { juice with sugar, sugarcane broth }\end{array}$ \\
\hline Natural spices & Garlic paste, garlic, onion \\
\hline $\begin{array}{l}\text { Breads, cookies, cakes } \\
\text { and pies }\end{array}$ & $\begin{array}{l}\text { Homemade bread, baguette bread, toast bread, cheese bread, biscuits, plain cake, corn bread, homemade } \\
\text { biscuit, sweet pies, sonho sweet bread }\end{array}$ \\
\hline Alcoholic beverages & Beer, wine, liquor, drip, whiskey, cognac \\
\hline Soda and juice & Industrialized juice (powder, boxed), normal soda, diet and light soda \\
\hline Coffee and tea & Coffee, tea, industrialized tea (green tea, iced tea, Herbalife ${ }^{\circledR}$ ) \\
\hline Sugar and candies & $\begin{array}{l}\text { Brown sugar, sweet rice, custard pudding, dulce de leche, ice cream, popsicle, candy, chewing gum, fruit } \\
\text { candy, açai with candy, bonbon, chocolate, chocolate powder }\end{array}$ \\
\hline Snacks & $\begin{array}{l}\text { Pizza, popcorn, hot mix, hamburger, fried snacks (puff pastry, quiche), roasted salads (pie, pie, roast pastry, } \\
\text { sfiha) }\end{array}$ \\
\hline Meat and dairy products & Beef or pork, almondegas, nuggets, hamburger steak, crackers and bacon \\
\hline Eggs & Eggs (cooked, scrambled, fried) \\
\hline Chicken and fish & Poultry and fish \\
\hline Oil and fat & $\begin{array}{l}\text { Olive oil, normal/light margarine, butter, vegetable mayonnaise, normal/light mayonnaise, potato chips, fried } \\
\text { cassava }\end{array}$ \\
\hline Whole grains & Oatmeal, granola, cereal bar, brown rice, brown bread, whole-wheat biscuit \\
\hline Skimmed milk & Semi-skimmed milk, skimmed milk \\
\hline
\end{tabular}

index $>3 \cdot 22$, regarding the 90th percentile of the sample); and systemic inflammation (high-sensitivity C-reactive protein $>6.07 \mathrm{mg} / \mathrm{l}$, regarding the 90th percentile of the sample $)^{(9)}$. Participants who presented two or more of these metabolic alterations were considered metabolically unhealthy. As mentioned above, participants were also classified according BMI as normal weight $\left(\mathrm{BMI} \leq 24.99 \mathrm{~kg} / \mathrm{m}^{2}\right)$ or overweight $\left(\mathrm{BMI} \geq 25.00 \mathrm{~kg} / \mathrm{m}^{2}\right.$ ). Finally, the participants were classified into four phenotypes based on their metabolic status and the presence or absence of overweight: MHNW, MUNW, MHOW and MUOW.

\section{Collection of food consumption data and covariables}

Food consumption data were collected through the FFQ developed and validated for the study population ${ }^{(21)}$. The FFQ included questions regarding the habitual consumption of ninety-five food items. The reference period was the 12 months prior to the interview and the frequency of consumption was 0-12 times per day, week, month or year. An FFQ item, soya milk, was excluded because its consumption frequency was less than $15 \%{ }^{(7)}$.

Additionally, we used a structured questionnaire composed of sociodemographic and behavioural questions. The covariables considered as potential confounders were: sex (male/female); age (continuous, in years); education ( $\leq 4,5-8,9-11$ or $\geq 12$ years); and physical activity level assessed by application of the International
Physical Activity Questionnaire (IPAQ), long version ${ }^{(22)}$ (defined as physically active ( $\geq 150 \mathrm{~min} /$ week) or inactive $<150 \mathrm{~min} /$ week) $)^{(9,23,24)}$.

\section{Data analysis}

In the analysis of dietary patterns, the ninety-five items of the FFQ were grouped into eighteen food groups (Table 1) and consumption was considered in grams, as a continuous variable. Dietary patterns were evaluated using the exploratory factor analysis methodology. The Kaiser-Mayer-Olkin coefficient, Bartlett's test of sphericity and communalites were calculated before the factor analysis to verify the applicability of the analysis. Subsequently, factors were excluded by using principal component analysis and orthogonal varimax rotation. Factors with eigenvalue $>1.5$ were retained, as defined by the scree plot of the variance $v$. the number of components. The exploratory factor structure was obtained from the indicators with an absolute factor loading greater than 0.20 and the dietary patterns were labelled according to the nutritional composition of the foods. Factor scores were categorized into quartiles and the first quartile was used as reference in all analyses ${ }^{(25)}$.

Multinomial logistic regression models were constructed to verify the association between dietary patterns (exposure variable) and metabolic phenotypes (outcome variable). The OR and their respective $95 \%$ CI were estimated for each dietary pattern analysed. All models were adjusted for age, sex, education and physical activity level, considered as 
Table 2 Dietary patterns derived from exploratory factor analysis of foods consumed by adults ( $n$ 896) aged 20-59 years of both sexes, Viçosa, Minas Gerais, Brazil, 2012-2014

\begin{tabular}{|c|c|c|c|c|}
\hline \multirow[b]{2}{*}{ Food group } & \multicolumn{3}{|c|}{ Dietary pattern } & \multirow[b]{2}{*}{ Communality } \\
\hline & Unhealthy & Traditional & Healthy & \\
\hline Spices & 0.658 & 0.078 & 0.012 & 0.5286 \\
\hline Alcoholic beverages & 0.644 & 0.209 & -0.070 & $0 \cdot 6146$ \\
\hline Snacks & 0.632 & -0.004 & 0.036 & 0.5006 \\
\hline Meat and dairy products & 0.481 & 0.448 & 0.139 & 0.4819 \\
\hline Oil and fat & 0.476 & 0.047 & -0.064 & 0.5370 \\
\hline Soda and juice & 0.401 & -0.257 & -0.057 & 0.4552 \\
\hline Sugar and candies & 0.340 & -0.213 & 0.080 & 0.5429 \\
\hline Chicken and fish & 0.295 & $0 \cdot 106$ & 0.463 & 0.5286 \\
\hline Eggs & 0.191 & 0.473 & 0.396 & 0.4496 \\
\hline Vegetables and fruits & -0.146 & 0.253 & 0.540 & 0.4920 \\
\hline Food \& beverage outlets & 0.144 & 0.584 & -0.158 & 0.5145 \\
\hline Breads, cookies, cakes and pies & 0.136 & 0.096 & -0.050 & 0.5006 \\
\hline Skimmed milk & 0.067 & -0.220 & 0.571 & 0.5736 \\
\hline Beans & 0.044 & 0.741 & -0.085 & 0.5792 \\
\hline Whole grains & 0.012 & -0.114 & 0.742 & 0.5993 \\
\hline Milk and dairy products & -0.035 & 0.257 & 0.029 & 0.6534 \\
\hline Coffee and tea & -0.066 & 0.233 & -0.072 & 0.4924 \\
\hline Natural spices & -0.087 & 0.111 & -0.005 & 0.5978 \\
\hline Eigenvalue & $2 \cdot 18$ & $1 \cdot 75$ & 1.62 & \\
\hline$\%$ variance explained & $12 \cdot 16$ & $9 \cdot 77$ & $9 \cdot 01$ & \\
\hline$\%$ acquired from the variance explained & $12 \cdot 16$ & 21.94 & 30.95 & \\
\hline
\end{tabular}

Bold values represent food groups kept in their related eating pattern.

potential confounders in the studied relationship ${ }^{(4,9)}$. The MHNW phenotype was used as a reference in all analyses. Additionally, the $\chi^{2}$ test for trend was used to assess the linear trend over the quartiles of food consumption. All analyses were conducted with the statistical software package Stata version 13.0 .

\section{Results}

Data from 896 individuals were evaluated. Over half the sample were women (55\%) and the mean age was 34 years (first quartile, 24 years; third quartile, 45 years). The sample consisted predominantly of individuals with more than 12 years of education (54.1\%), non-white $(57.3 \%)$, without a partner $(54.9 \%)$ and of intermediate socio-economic level (66.5\%). The majority reported no alcoholic beverage consumption (60.2\%), no smoking (69.5\%) and physical inactivity (69.3\%). The MHNW metabolic phenotype was the most prevalent (44.3\%), followed by the MUOW and MHOW phenotypes, which presented similar prevalence $(23.0$ and $22.7 \%$, respectively). The MUNW phenotype was identified in $10.0 \%$ of the sample.

The food items of the FFQ were grouped into food groups, as shown in Table 2.

The use of exploratory factor analysis to evaluate the data was satisfactory (Kaiser-Mayer-Olkin coefficient $=0.73$ and Bartlett's test of sphericity $=0.40$ ). It was possible to identify three eating patterns in the study population, with eigenvalues above 1.5 , which explained $30.95 \%$ of the total variance in food intake. Food groups with an absolute factor loading greater than 0.20 were considered valid in the dietary patterns, with each pattern being composed of the food groups with the highest factor loadings (Table 2).

The patterns identified were: (i) Unhealthy pattern, composed of alcoholic beverages, oils and fats, condiments, soda and juice, sugars and sweets, snacks, and meats and derivatives; (ii) Traditional pattern, composed of food groups of culinary preparations, beans, milk and dairy products, and coffee and tea; and (ii) Healthy pattern, composed of vegetables and fruits, whole grains, chicken and fish, and skimmed milk (Table 2).

In Table 3, the OR and $95 \%$ CI for the association of the three identified dietary patterns with the metabolic phenotypes can be observed with reference to the first quartile of consumption. The fourth quartile of consumption of the Unhealthy pattern was associated with an $84 \%$ increase in the chance of occurrence of MHOW phenotype $(\mathrm{OR}=1.84 ; 95 \% \mathrm{CI} 1 \cdot 06,3 \cdot 22)$, and the third and fourth quartiles were associated with an increase of $94 \%$ $(\mathrm{OR}=1.94 ; 95 \% \mathrm{CI} 1.11,3.39)$ and $156 \%(\mathrm{OR}=2.56 ; 95 \%$ CI 1.41, 4.64), respectively, in the chance MUOW phenotype occurrence. The Healthy pattern was also associated with the MHOW phenotype in a positive way, with a $70 \%$ increase in the chance of occurrence of this phenotype in the fourth quartile of consumption (OR $=1 \cdot 70 ; 95 \%$ CI 1.01, 2.86). This pattern was also associated with the MUOW phenotype in all quartiles of consumption, with an increase in the phenotype's chance of occurrence of $115 \%(\mathrm{OR}=2 \cdot 15$; $95 \%$ CI $1.23,3.76), 191 \%(\mathrm{OR}=2.91 ; 95 \%$ CI $1.68,5.04)$ and $198 \%(\mathrm{OR}=2.98 ; 95 \% \mathrm{CI} 1.65,5.37)$ for the second, 
Table 3 Association between dietary patterns and metabolic phenotypes among adults $(n$ 896) aged $20-59$ years of both sexes, Viçosa, Minas Gerais, Brazil, 2012-2014

\begin{tabular}{|c|c|c|c|c|c|c|c|c|c|}
\hline \multirow[b]{3}{*}{ Dietary pattern } & \multicolumn{9}{|c|}{ Metabolic phenotype (Ref.: MHNW) } \\
\hline & \multicolumn{3}{|c|}{ MHOW } & \multicolumn{3}{|c|}{ MUNW } & \multicolumn{3}{|c|}{ MUOW } \\
\hline & OR & $95 \% \mathrm{Cl}$ & $P$ & OR & $95 \% \mathrm{Cl}$ & $P$ & OR & $95 \% \mathrm{Cl}$ & $P$ \\
\hline \multicolumn{10}{|c|}{ Unhealthy pattern } \\
\hline Quartile 1 & Ref. & - & - & Ref. & - & - & Ref. & - & - \\
\hline Quartile 2 & 1.36 & $0.81,2.29$ & 0.233 & 0.77 & $0.40,1.46$ & 0.42 & 1.41 & $0.83,2.40$ & 0.197 \\
\hline Quartile 3 & 1.32 & $0 \cdot 77,2 \cdot 28$ & 0.301 & 0.75 & $0.37,1.49$ & 0.41 & 1.94 & $1 \cdot 11,3.39$ & 0.019 \\
\hline Quartile 4 & 1.84 & $1.06,3 \cdot 22$ & 0.030 & 0.88 & $0.42,1.81$ & 0.73 & 2.56 & $1.41,4.64$ & 0.002 \\
\hline \multicolumn{10}{|c|}{ Traditional pattern } \\
\hline Quartile 1 & Ref. & - & - & Ref. & - & - & Ref. & - & - \\
\hline Quartile 2 & 0.86 & $0.53,1.41$ & 0.565 & 0.78 & $0.40,1.49$ & 0.455 & 0.79 & $0.46,1.35$ & 0.398 \\
\hline Quartile 3 & 0.90 & $0.54,1.50$ & 0.712 & 0.74 & $0.37,1.48$ & 0.406 & 0.92 & $0.53,1.58$ & 0.765 \\
\hline Quartile 4 & 0.68 & $0.40,1.17$ & 0.170 & 0.81 & $0.40,1.63$ & 0.568 & 0.86 & $0.49,1.51$ & 0.613 \\
\hline \multicolumn{10}{|l|}{ Healthy pattern } \\
\hline Quartile 1 & Ref. & - & - & Ref. & - & - & Ref. & - & - \\
\hline Quartile 2 & 1.40 & $0 \cdot 86,2 \cdot 26$ & 0.167 & 0.93 & $0.48,1.80$ & 0.845 & $2 \cdot 15$ & $1.23,3.76$ & 0.007 \\
\hline Quartile 3 & 1.28 & $0.77,2 \cdot 13$ & 0.322 & 1.01 & $0.52,1.95$ & 0.971 & $2 \cdot 91$ & $1.68,5.04$ & $<0.001$ \\
\hline Quartile 4 & $1 \cdot 70$ & $1 \cdot 01,2 \cdot 86$ & 0.042 & $1 \cdot 21$ & $0.61,2.41$ & 0.578 & 2.98 & $1 \cdot 65,5 \cdot 37$ & $<0.001$ \\
\hline
\end{tabular}

Ref., reference category; MHNW, metabolically healthy normal weight; MHOW, metabolically healthy overweight; MUNW, metabolically unhealthy normal weight; MUOW, metabolically unhealthy overweight.

Models are adjusted for age, sex, education and physical activity.

third and fourth quartile of consumption, respectively. The Traditional pattern, on the other hand, was not associated with metabolic phenotypes.

A significant linear trend was observed only for the relationship between the Healthy pattern and MUOW $\left(P_{\text {trend }}<0 \cdot 01\right)$.

\section{Discussion}

To the best of our knowledge, the present study is the first to investigate the relationship of dietary patterns with metabolic phenotypes in Brazilian adults. The results indicated a positive association between the identified Unhealthy and Healthy dietary patterns and the overweight phenotypes (MHOW and MUOW). On the other hand, there were no significant associations of these patterns with the MUNW phenotype nor of the Traditional pattern with any of the evaluated phenotypes.

In studies on the association between dietary patterns and metabolic phenotypes, results similar to our study were observed. In investigations carried out with the American population, individuals with MUOW showed significantly higher consumption of red meat, processed meat and fried foods when compared with those with $\mathrm{MHNW}^{(16,18)}$. These foods compose the Unhealthy pattern identified in our study, which was also positively associated with the MUOW and MHOW phenotypes. Likewise, other authors have associated patterns with high energy content to increased risk of metabolic disorders and weight gain ${ }^{(3,4,7)}$.

Among the biological mechanisms that may explain this relationship, high consumption of high-energy foods influences the profile of adipokine secretion, insulin sensitivity and endothelial function, besides promoting changes in the intestinal microbiota affecting energetic homeostasis and lipid accumulation ${ }^{(26,27)}$. These alterations are associated with increased risk of metabolic disturbances and weight gain ${ }^{(4,28)}$. On the other hand, the high consumption of healthy foods has been pointed out as a protective behaviour because of their high fibre content and low energy density ${ }^{(29)}$. Moreover, diets based on unprocessed and minimally processed foods have been associated with lower glycaemic response and higher satiety $^{(26)}$

The Healthy pattern identified in the current study presents characteristics of a healthy dietary pattern. This pattern is similar to those found in other studies which include white meat, whole grains, fruits and vegetables in their composition ${ }^{(24,26)}$. However, this pattern was positively associated with MUOW in the current study, as observed in other studies assessing dietary patterns' association with body adiposity ${ }^{(7,15)}$. These results can be explained, at least in part, by the under-reporting of high-energy foods and the over-reporting of healthy foods by overweight individuals ${ }^{(29,30)}$. In addition, given the cross-sectional nature of our study, reverse causality is possible since overweight people may have changed their eating habits in order to control body weight.

Our study presents strengths such as the use of different quality assurance and quality control strategies and the use of an FFQ developed and validated for the population assessed. Among the limitations, information bias cannot be ruled out since, as already pointed out, the under- or over-reporting of foods composing the dietary patterns, especially among obese individuals, may have contributed to the positive associations observed. 


\section{Conclusion}

In conclusion, in the present study, the more energydense dietary pattern was related to excess weight phenotypes. In addition, the healthier dietary pattern was also related to these phenotypes, probably due to underand over-reporting of foods by overweight individuals and reverse causality. More studies are necessary to evaluate the relationship between dietary patterns and metabolic phenotypes for a more targeted nutritional recommendation.

\section{Acknowledgements}

Acknowledgements: The authors are grateful to the collaborators for the development of this study, the volunteers who participated in the research and the funding sources. Financial support: During the 24-month period of research data analysis, author D.L.M.P. received financial support from the Coordination for the Improvement of Higher Education Personnel (CAPES). CAPES had no additional role in the design, analysis or writing of this article. Conflict of interest: The authors declare to have no conflict of interest with the topic addressed. Authorship: D.L.M.P. and L.L.J. participated in the conception and design of the manuscript, statistical analysis, data interpretation and manuscript drafting. D.C.G.S. participated in the conception and design of the manuscript, data interpretation and helped write the manuscript. L.L.J. and D.C.G.S. participated in statistical analysis, data interpretation and contributed intellectual content to the paper. G.Z.L. conceived the study, participated in its design and coordination, and contributed intellectual content to the paper. All authors have read and approved the final manuscript. Ethics of buman subject participation: This study was carried out in accordance with the guidelines established in the Declaration of Helsinki and all procedures involving research participants were approved by the Ethics and Research Committee of the Federal University of Viçosa (opinion number 008/2012). Written informed consent was obtained from all participants.

\section{References}

1. Sichieri R (2002) Dietary patterns and their associations with obesity in the Brazilian city of Rio de Janeiro. Obes Res $\mathbf{1 0}$, 42-48.

2. Marchioni DM, Claro RM, Levy RB et al. (2011) Patterns of food acquisition in Brazilian households and associated factors: a population-based survey. Public Health Nutr 14, $1586-1592$.

3. Neumann AICP, Martins IS, Marcopito LF et al. (2007) Padrões alimentares associados a fatores de risco para doenças cardiovasculares entre residentes de um município brasileiro. Rev Panam Salud Pública 22, 329-339.
4. Rodrigues PRM, Pereira RA, Cunha DB et al. (2012) Fatores associados a padrões alimentares em adolescentes: um estudo de base escolar em Cuiabá, Mato Grosso. Rev Bras Epidemiol 15, 662-674.

5. Moreira PL, Corrente JE, Boas PJFV et al. (2014) Dietary patterns are associated with general and central obesity in elderly living in a Brazilian city. Rev Assoc Med Bras 60, 457-464.

6. Silva DF de O, Lyra C de O \& Lima SCVC (2016) Padrões alimentares de adolescentes e associação com fatores de risco cardiovascular: uma revisão sistemática. Cien Saude Colet 21, 1181-1196.

7. Silva DCG da, Pereira KA da C, Segheto W et al. (2017) Associação de padrões alimentares e adiposidade abdominal em adultos brasileiros. Rev Nutr 30, 783-793.

8. Hoffmann M, Mendes KG, Canuto R et al. (2015) Padrões alimentares de mulheres no climatério em atendimento ambulatorial no Sul do Brasil. Cien Saude Colet 20, 15651574.

9. Wildman RP, Muntner P, Reynolds K et al. (2008) The obese without cardiometabolic risk factor clustering and the normal weight with cardiometabolic risk factor clustering. $A r c h$ Intern Med 168, 1617-1624.

10. Phillips CM (2017) Metabolically healthy obesity across the life course: epidemiology, determinants, and implications. Ann N Y Acad Sci 1391, 85-100.

11. Roberson L, Shaharyar S, Aneni E et al. (2014) The prevalence of the metabolically healthy obese phenotype in an aging population and its association with subclinical cardiovascular disease: the Brazilian study on healthy aging. Diabetol Metab Syndr 6, 121.

12. Diniz MDFHS, Beleigoli AMR, Ribeiro ALP et al. (2016) Factors associated with metabolically healthy status in obesity, overweight, and normal weight at baseline of ELSA-Brasil. Medicine (Baltimore) 95, e4010.

13. Xia L, Dong F, Gong H et al. (2017) Association between indices of body composition and abnormal metabolic phenotype in normal-weight Chinese adults. Int J Environ Res Public Health 14, 391.

14. Goday A, Calvo E, Vázquez LA et al. (2016) Prevalence and clinical characteristics of metabolically healthy obese individuals and other obese/non-obese metabolic phenotypes in a working population: results from the Icaria study. $B M C$ Public Health 16, 248.

15. Perozzo G, Olinto MTA, Dias-da-Costa JS et al. (2008) Associação dos padrões alimentares com obesidade geral e abdominal em mulheres residentes no Sul do Brasil. Cad Saude Publica 24, 2427-2439.

16. Kimokoti RW, Judd SE, Shikany JM et al. (2015) Metabolically healthy obesity is not associated with food intake in white or black men. J Nutr 145, 2551-2561.

17. Fung TT, Rimm EB, Spiegelman D et al. (2001) Association between dietary patterns and plasma biomarkers of obesity and cardiovascular disease risk. Am J Clin Nutr 73, 61-67.

18. Kimokoti RW, Judd SE, Shikany JM et al. (2014) Food intake does not differ between obese women who are metabolically healthy or abnormal. J Nutr 144, 2018-2026.

19. Segheto W, Cristina Guimarães da Silva D, Araújo Coelho F et al. (2015) Body adiposity index and associated factors in adults: method and logistics of a population-based study. Nutr Hosp 32, 101-109.

20. World Health Organization (1995) Physical Status: The Use and Interpretation of Anthropometry. Report of a WHO Expert Committee. WHO Technical Report Series no. 854. Geneva: WHO.

21. da Silva DCG, Segheto W, de Lima MFC et al. (2018) Using the method of triads in the validation of a food frequency questionnaire to assess the consumption of fatty acids in adults. J Hum Nutr Diet 31, 85-95. 
22. Pardini R (2001) Validação do questionário internacional de nível de atividade fisica (IPAQ- versão 6) estudo piloto em adultos jovens brasileiros. Rev Bras Cienc Mov 9, $45-51$.

23. Haskell WL (2007) Physical activity and public health updated recommendation for adults from the American College of Sports Medicine and the American Heart Association. Circulation 116, 1081-1094.

24. Pinho LDe, Silveira MF, Botelho ACDC et al. (2014) Identificação de padrões alimentares de adolescentes de escolas públicas. J Pediatr (Rio J) $\mathbf{9 0}$ 267-272.

25. Olinto MT, Kag G \& Sichieri RGD (2007) Padrões alimentares: análise dos componentes principais. In Epidemiologia Nutricional, pp. 213-226. Rio de Janeiro: Editora Fiocruz/ Editora Atheneu.
26. Fardet A (2016) Minimally processed foods are more satiating and less hyperglycemic than ultra-processed foods: a preliminary study with 98 ready-to-eat foods. Food Funct 7, $2338-2346$.

27. de Moraes ACF, Adami F \& Falcão MC (2012) Understanding the correlates of adolescents' dietary intake patterns. A multivariate analysis. Appetite 58, 1057-1062.

28. Salvatti AG, Escrivão MAMS, Taddei JAdeAC et al. (2011) Padrões alimentares de adolescentes na cidade de São Paulo. Rev Nutr 24, 703-713.

29. Pomerleau J, Østbye T \& Bright-See E (1999) Potential underreporting of energy intake in the Ontario Health Survey and its relationship with nutrient and food intakes. Eur J Epidemiol 15, 553-557.

30. Lissner L, Heitmann BL \& Bengtsson C (2000) Population studies of diet and obesity. BrJ Nutr 83, Suppl. 1, S21-S24. 